BOOK REVIEW

\section{Abortion Law in Transnational Perspective: Cases and Controversies}

\author{
Cook RJ, Erdman JN, Dickens BM (eds). \\ Philadelphia, PA: University of Pennsylvania \\ Press, 2014. ISBN-13: 978-0-812-24627-8. \\ Price: $£ 45.50$. Pages: 480 (hardback)
}

This is a 16-chapter book written entirely by lawyers. It is edited by three eminent lawyers who developed the renowned International Reproductive and Sexual Health Law Program at the University of Toronto. It is aimed at those with a legal background. Will those from other disciplines benefit from reading it?

I would say it is well worth dipping in to. All chapters are written to a high standard of scholarship and in a lucid and accessible style. The chapters that cover constitutional law are admittedly quite challenging. But the concept of the diametrically opposed constitutional stances in the USA and Germany is fundamental to an appreciation of the development of laws around the world. It is a paradox that in Germany, with its abortion-dissuasive counselling regime, abortion is freely available and largely state-funded; in the USA despite the freedom to choose emanating from Roe $v$ Wade, restrictions have been imposed as a result of political pressure in most states.

The book refers to two main models of abortion law. The indications model in which certain conditions need to be satisfied in order that an abortion can go ahead and the periodic model in which women can request an abortion up to a specified gestational limit. The periodic model is tending to supersede the indications model as a more progressive type of law.

There are chapters that describe evolution of the law in specific countries: Portugal, Slovakia, Argentina, Brazil, the UK and Nepal. The contexts are varied but general points of principle are made. The magnitude of the transformation in Nepal is extraordinary.

Several chapters make the overall point that liberalised laws do not necessary translate into good access to abortion. Implementation of laws is needed too, and countries can be held accountable if they fail in this respect. Officially approved clinical or public health guidelines make a difference here, as do availability and facilitation of mid-level providers.

Criminal laws governing abortion are roundly criticised by the authors. Other informal law and background rules can further restrict access to otherwise legal abortion; the case of Poland is mentioned over and over, with detailed citations from the leading European Court of Human Rights cases.

Two chapters stand out to me as being particularly valuable, with potential for translation into improvements in service provision. Bernard Dickens' comprehensive chapter on 'The Right to Conscience' is masterly. Rebecca Cook's chapter 'Stigmatized Meanings of Criminal Abortion Law' on how the criminal law creates stereotyping and stigma is highly original, applying social psychology to legal thinking.

Reviewed by Sam Rowlands

Visiting Professor, School of Health and Social Care, Bournemouth University, Bournemouth, UK ; srowlands@bournemouth.ac.uk

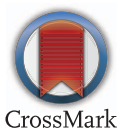

J Fam Plann Reprod Health Care 2015;41:204 doi:10.1136/jprhc-2014-101162 